\title{
ANÁLISE QUALITATIVA DA EVAPOTRANSPIRAÇÃO HORÁRIA E SUA COMPARAÇÃO COM O SALDO DE RADIAÇÃO
}

\author{
Camilla K. Borges ${ }^{1}$, Carlos A. C. dos Santos $^{1}$, Raimundo M. de Medeiros ${ }^{1}$ \\ 1Universidade Federal de Campina Grande e-mail: camillakassar@gmail.com
}

\section{RESUMO}

Este estudo teve como objetivo comparar o saldo de radiação $(R n)$ à superfície com a evapotranspiração horária $\left(E T_{h}\right)$ estimada via SEBAL e S-SEBI, para pomar de bananeiras (Musa sp.) da Fazenda Frutacor (Quixeré - CE), além de sua distribuição espacial nessa área. Foram constatadas similaridades entre o SEBAL e o S-SEBI na distribuição espacial das superfícies secas e úmidas, porém com maior precisão para o SEBAL.

\begin{abstract}
This study aimed to compare the net radiation $(\mathrm{Rn})$ to the surface with the hourly evapotranspiration (ETh) estimated through SEBAL and S-SEBI for orchard of banana (Musa sp.) of Farm Frutacor (Quixeré - EC), and spatial distribution in this area. Similarities were observed between SEBAL and S-SEBI in the spatial distribution of dry and wet surfaces, but with more precision for the SEBAL.
\end{abstract}

\section{INTRODUÇÃO}

Para o manejo hídrico adequado de uma cultura, é de grande importância o conhecimento da evapotranspiração $(E T)$, que pode ser estimada através de técnicas de sensoriamento remoto orbital com boa precisão (Ziany et al., 2011).

Um dos dois algoritmos utilizados com esse objetivo é o SEBAL (Surface Energy Balance Algorithm for Land), validado em várias partes do mundo e faz uso das radiâncias espectrais registradas em sensores de satélites e um conjunto mínimo de dados de superfície para obter as componentes do balanço de energia $(B E)$. Já o S-SEBI (Simplified Surface Energy Balance Index) representa uma metodologia mais simplificada, baseada no contraste da fração evaporativa ( $($ ) entre áreas secas e úmidas (Santos, 2009).

Desta forma, este estudo tem o objetivo de comparar o saldo de radiação $(R n)$ - radiação líquida à superfície com a $E T$ horária $\left(E T_{h}\right)$ estimada via SEBAL e S-SEBI do pomar de bananeiras (Musa sp.) da Fazenda Frutacor (Quixeré - CE), além de sua distribuição espacial nessa área.

\section{MATERIAIS E MÉTODOS}

Processaram-se imagens do satélite Landsat 5-TM, dos dias 24/10/2005 e 08/08/2006, correspondentes aos dias de ordem do ano (DOA), 297 e 220, respectivamente.

Para o cálculo do fluxo de calor no solo $(G)$ e $R n\left(W^{-2}\right)$ tem-se a metodologia adotada por Santos (2009) aplicada para o SEBAL e S-SEBI.

O fluxo de calor sensível $H\left(W^{-2}\right)$ estimado pelo SEBAL foi obtida através de processo iterativo baseado na teoria da similaridade de Monin-Obukhov (Ziany et al., 2011; Santos, 2009). O fluxo de calor latente ( $L E$ ) provém como resíduo da equação do $B E$ (Santos, 2009). 
Enquanto, no S-SEBI tanto $L E$ como $H$ são obtidos com base no albedo e na temperatura da superfície para obter-se a $\Lambda$.

A $E T_{h}$ em $m m h^{-1}$ é fornecida através do $L E$ estimados pelo SEBAL e S-SEBI (Santos, 2009).

\section{RESULTADOS E DISCUSSÃO}

Verificou-se comportamento semelhante da $E T_{h}$ com $R n$ (Figuras 1a e 1b), isto é, quanto maior ou menor a energia radiante disponível à superfície (para os processos físicos biológicos), o $L E$ associado a $E T$ apresenta padrão semelhante, exceto o pixel de número 6, com um máximo em torno de $670 \mathrm{Wm}^{-2}$ e decréscimo na $E T_{h}$. Verifica-se também ligeiras diferenças entre a $E T_{h}$ do modelo S-SEBI (Figura 1 b) em relação ao SEBAL, o que pode estar associado às diferenças nas metodologias de obtenção do fluxos $L E$.

A Figura 1c apresentou maiores divergências no comportamento da $E T_{h}$ com o $R n$, sendo mais evidente na Figura 1d, pois trata-se de um período ainda com bastante umidade no solo, não apresentando grandes contraste entre áreas secas e úmidas.

Observou-se semelhanças na distribuição espacial da $E T_{h}$ do S-SEBI (Figura 2b) com o SEBAL (Figura 2a) que possui um refinamento melhor. E, na Figura $2 \mathrm{c}$ se nota as poucas áreas secas, e úmidas mais bem definidas que na Figura 2d.

\section{CONCLUSÕES}

De maneira geral, a $E T_{h}$ em relação ao $R n$ apresentaram padrões semelhantes, porém com ligeiras diferenças possivelmente associadas às diferenças nas metodologias e aos distintas períodos (seco para 297 e úmido para 220). E, também, constaram-se similaridades entre o SEBAL e o S-SEBI na espacialidade das áreas secas e úmidas, porém com maior precisão para o SEBAL.

\section{REFERÊNCIAS}

Allen, R. G.; Pereira, L. S.; Raes, D.; Smith, m. Crop evapotranspiration - Guidelines for computing crop water requirements - FAO Irrigation and drainage paper 56. Rome-Italy, 1998.

Santos, C. A. C. Estimativa da Evapotranspiração Real Diária Através de Análises Micrometeorológicas e de Sensoriamento Remoto. 2009. 143 f. Tese (Doutorado em Meteorologia) - Centro de Tecnologia e Recursos Naturais, Universidade Federal de Campina Grande, Campina Grande. 2009.

Ziany, N. B., Sofiatti, V., Bezerra, B. G., Bezerra, J. R. C., Medeiros, J. C. Estimativa da necessidade hídrica do algodoeiro irrigado usando imagens de satélite. In: SIMPÓSIO BRASILEIRO DE SENSORIAMENTO REMOTO, 15., 2011, Curitiba - PR. Anais... Curitiba: INPE, 2011.p. 0653 - 0658. 
DOI: $10.5902 / 2179460 X 11555$

Revista do Centro de Ciências Naturais e Exatas - UFSM

Revista Ciência e Natura, Santa Maria

EISSN: 2179-460X, Edição Esp. Dez. 2013, p. 090 - 092

\section{ciênciaenatura}

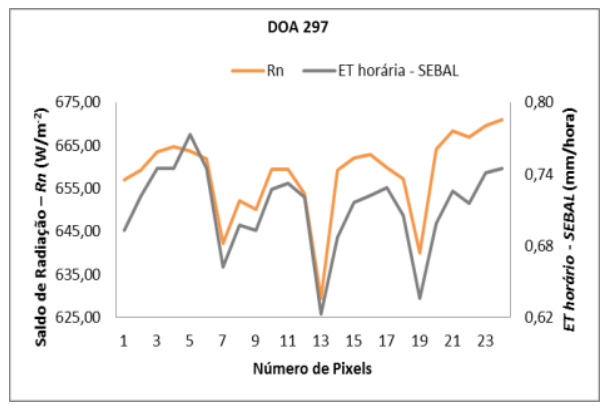

a)

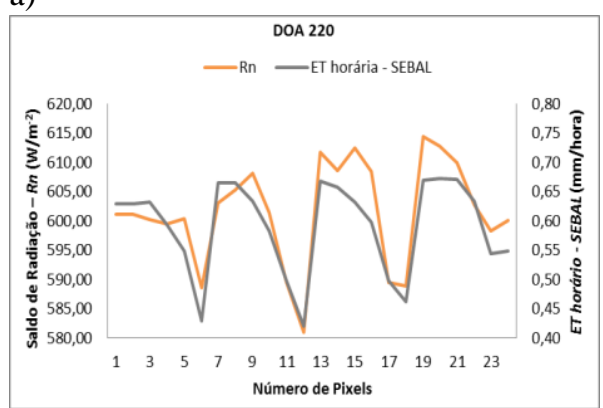

c)

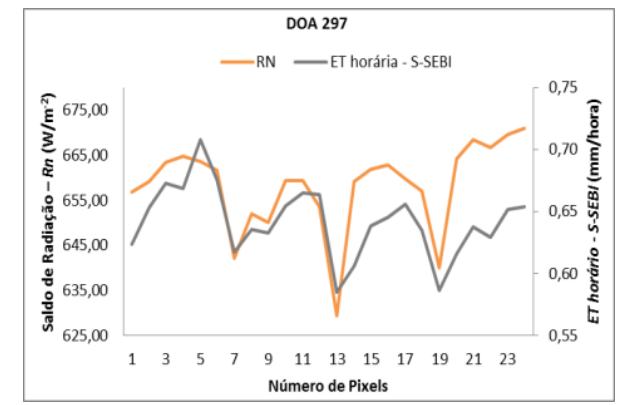

b)

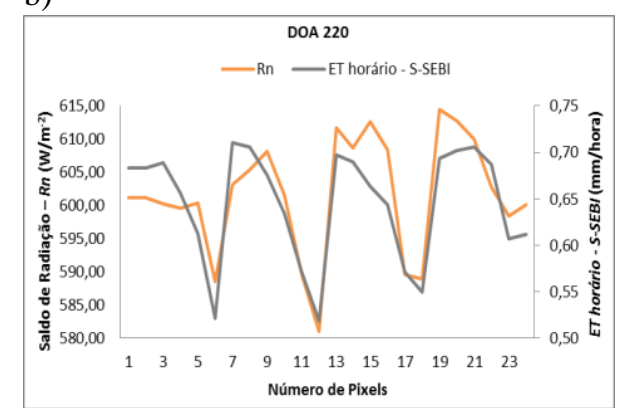

d)

Figura 1 - Comparação entre o saldo de radiação $(R n)$ com a evapotranspiração horária $\left(E T_{h}\right)$ estimados pelos modelos SEBAL nos dias 297 e 220 (a, c) e S-SEBI nos dias 297 e 220 (b,d).

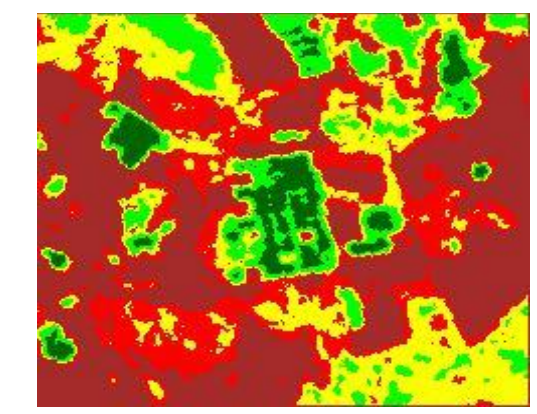

a)

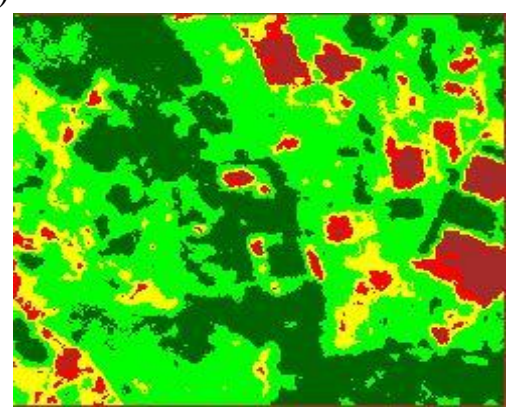

c)

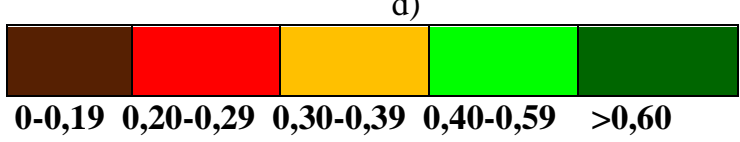

b)
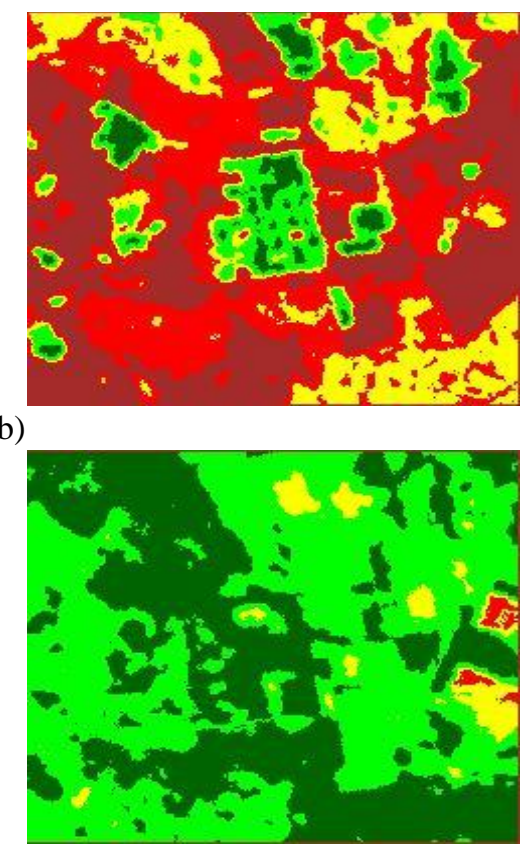

(2006) através do SEBAL (a, c), $\mathrm{S}$-SEBI $(\mathrm{b}, \mathrm{d})$ e sua respectiva paleta de cores. 